\title{
Psychological Distress and Social Support among Conflict Refugees in Urban, Semi-rural and Rural Settlements in Uganda: Burden and Mechanisms of Association
}

\section{Stephen Lawoko ( $\nabla$ s.lawoko@gu.ac.ug )}

Gulu University Faculty of Medicine https://orcid.org/0000-0003-4369-7955

\section{Catherine Nakidde}

Centre for Health and Socio-economic Improvement

\section{Eric Lugada}

Centre for Health and Socio-economic Improvement

Maria Ssematiko

Centre for Health and Socio-economic Improvement

\section{Dunstan P. Ddamulira}

Agency for Cooperation and Research in Development (ACORD)

\section{Andrew Masaba}

Lutheran World Federation

\section{Brian Luswata}

Directorate of Governance and Regulation, inistry of Health and Community Service: Ministry of Health Community Development Gender Elderly and Children

\section{Eric A. Ochen}

Makerere University College of Humanities and Social Sciences

\section{Betty Okot}

Makerere University College of Humanities and Social Sciences

\section{Denis Muhangi}

Makerere University College of Humanities and Social Sciences

\section{Gloria Seruwagi}

Makerere University College of Humanities and Social Sciences

\section{Research}

Keywords: Psychological Distress, Social Support, MHPSS, COVID-19, Urban/Rural, Conflict Refugees, Uganda

Posted Date: June 16th, 2021 
DOl: https://doi.org/10.21203/rs.3.rs-606878/v1

License: (c) (1) This work is licensed under a Creative Commons Attribution 4.0 International License. Read Full License 


\section{Abstract}

Background: Recent research shows that psychological distress is on the rise globally as a result of the COVID-19 pandemic and restrictions imposed on populations to manage it. We estimated the burden of psychological distress and scrutinized the role that social support may play in moderating psychological distress among conflict refugees in urban, semi-rural and rural settlements in Uganda during the COVID19 pandemic.

Methods: Cross-sectional survey data on psychological distress, social support, demographics, socioeconomic and behavioral variables was gathered from 1014 adult refugees randomly sampled from urban, semi-rural and rural refugee settlementsin Uganda, using two-staged cluster sampling. Research instruments were checked for reliability using Cronbach's Alpha. T-test, Analysis of Variance (ANOVA) and Multivariable Linear Regression were applied to analyse the data in SPSS-version 22. Statistical significance was assumed at $p<0.05$.

Results: Refugees resident in rural/semi-rural settlements exhibited higher levels of psychological distress, lower levels of social interaction and lower levels of social attachment than peers resident in urban settlements. However, they reported, on the other hand, higher adequacy of social interaction and higher adequacy of social attachment than peers resident in urban settlements. Adequacy of social interaction and attachment were directly associated with psychological distress and acted as stress buffers in the relationship between psychological distress and rural/urban settlement.

Conclusions: There is a settlement-inequality (i.e. rural vs. urban) in psychological distress and social support among conflict refugees in Uganda. Both the direct and buffering effects of adequacy of social interaction and attachment can explain the rural/urban discrepancy in psychological distress, with important implications for Mental Health and Psychosocial Support (MHPSS) interventions.

\section{Introduction}

COVID-19 has exasperated the health and wellbeing of population groups worldwide since it was declared a pandemic over a year ago. Beside the fear, anxiety, confusion, and frustrations triggered by the pandemic per se [1], the stringent measures activated by governments to curtail the disease spread have further exacerbated psychological distress. Globally, experts predict that the collective impact of these restrictions on household socio-economics, health and wellbeing, as well as the social infrastructure of communities will extend beyond the lifespan of the pandemic [1-7]. These trends are further manifest in the increasing burden of intimate partner violence, depression and anxiety [8-12].

Despite the growing body of evidence suggesting deteriorating psychosocial wellbeing at population level, equivocal data from refugee populations is lacking. Currently surpassing 80 million in number globally, conflict refugees are particularly at heightened risk of psychological distress when contrasted with host communities. A myriad of psychosocial problems including Post-Traumatic Stress Disorder (PTSD), depression and anxiety [13-14], and psychological distress triggered by fears of apprehension, 
risk of deportation, difficult living conditions, poor access to health, social, communication, financial and legal services [15-21], have been reported in refugee settings. This is in addition to the stressors imposed by restrictions to contain COVID-19 pandemic at the population level [1-7]. An assessment of psychological distress status and psychosocial support needs for refugees is therefore particularly imperative in the pandemic era.

Social support can play an important role in preventing, containing or moderating the psychological wellbeing of populations through several mechanisms. While some scholars have emphasized its role as a stress buffer [22-23], others have highlighted its protective function as a coping facilitator [24-25] as well as its role in health promotion [26]. As a stress buffer, social support is envisioned to alleviate the detrimental impact of stressful life events by modifying negative appraisals and promoting problem solving strategies [24, 26-27]. Some scholars argue however that during times of severe or chronic distress, the buffering effect of support may be limited [28-29]. In contrast, as a coping facilitator, social support is envisaged to provide regular directly rewarding experiences such as positive affection, which prevent the development of psychologically distressful outcomes [22, 26]. Moreover, a supportive network is hypothesized to promote behaviors beneficial to health such as timely seeking of healthcare and adaptation of healthy lifestyles (e.g. healthy nutritional choices and physical activity) [24,26-27], thereby reducing the likelihood of psychological distress.

Although population studies have alluded to a breakdown in social support networks during the COVID-19 pandemic, there is a dearth of studies investigating its role in containing psychological distress particularly in refugee populations where the need is augmented. Moreover, refugees live under varying conditions with some residing in urban and others in rural settings, and this has implications on vulnerability to health problems. For instance, it could be assumed that urban refugees may be more prone to social support by virtue of the vast availability of social networks or opportunities for social interaction (e.g. through gainful employment) on the one hand, but may on the other hand be confronted with challenges related with psychological stressors that accompany increased population density and diversity in cities such as unemployment, violence, marginalization and exposure to health-risk behaviours [30-32]. Moreover, settlement of refugees in rural/urban areas have in some countries been characterised by cultural homogeneity, and culture is known to play an important role in social integration. In Uganda the context of the current study for example, South Sudanese, Congolese and Somali refugees have been resettled in rural, semi-rural and urban settlements respectively. While on the one hand the collectivist orientation of such settlements may promote social interaction by virtue of shared cultural norms and interest, efforts to integrate into a new society or culture may discourage such intentions [33-34]. Thus, an assessment of the nature of relationship between social support and psychological distress in distinct settlements (i.e. urban vs. rural) is warranted on its own right.

Upon this background, we scrutinized social support and psychological distress, and compared the impact of social support on psychological distress among refugees in urban, semi-rural and rural settlements in Uganda. Specifically, we addressed the following research questions: 
1. How do refugees in urban, semi-rural and rural settlements in Uganda rate their levels of psychological distress during the COVID-19 pandemic? In other words, what is the burden of psychological distress among refugees in urban, semi-rural and rural settlements in Uganda?

2. How do refugees in urban, semi-rural and rural settlements in Uganda rate their availability and adequacy of social support during the COVID-19 pandemic?

3. What is the mechanism linking social support to psychological distress? Does social support impact directly (independently) on psychological distress and/or Does social support buffer psychological distress resulting from urban/rural residency among refugees?

\section{Methods}

\section{Study Context}

Uganda is host to nearly1.5 million conflict refugees from neighbouring countries of Rwanda, Burundi, South Sudan and Democratic Republic [35]. These refugees exhibitpoor living conditions, pre-existing mental and psychosocial challenges [36-40]. The inaction caused byCOVID-19 preventive measures, starting from the first case identification on 21 March 2020, including restrictions on mass gatherings, public transport, entry and exit at border points, and lockdown on several social services [41] is envisioned to have impacted further on psychological distress in this already vulnerable population. Indeed, emerging data in vulnerable groups of refugee women and slum-dwellers have catapulted their risk to stigma, all forms of violence and financial disadvantage [42-43]. While researchers have predicted the economic, psychosocial, physical, and other consequences of COVID-19 on refugees/migrants in Uganda and beyond based on previous epidemics [44-47], there is a dearth of evidence on the burden of psychological distress, social support and mechanisms linking these phenomena in refugee settings during the COVID-19 pandemic. The current work intends to fill this gap in the evidence using Uganda as a case study. Such data could be useful in the design of interventions to cushion psychosocial problems among refugees through the modification of social support agents.

\section{Study site and population}

We conducted the research at 3 large refugee settlements in different regions of Uganda, hosting over 400,000 refugees:

1. Kisenyi, refugee settlement, an urban refugee setting in the centre of the capital city (Kampala) hosting over 70,000 refugees of mainly Somali origin. The refugees live integrated with their host.

2. Kyaka II refugee Settlement in the South Western part of Uganda, a semi-rural refugee setting hosting multinational refugees from the Democratic Republic of Congo (DRC), Burundi and Rwanda totaling approximately 124,000 refugees. The refugees live partly segregated from their host but with freedom of movement and shared services. The region can be considered as semi-rural, with a blend of rural and urban activities (e.g. farming, industrial activities)

3. Adjumani refugee settlement in North-West Nile Uganda, hosting about 214,000 refugees predominantly of South Sudanese nationality. The refugees live rather segregated from their host but 
with freedom of movement and shared services. The region is considered as rural, with Agriculture as main activity.

\section{Study design}

Cross-sectional survey data on various health and social indicators was gathered from 1014 refugees randomly selected from each of the study sites. For the current study, data on psychological distress, social support, demographic, social and behavioral indicators was of primary interest.

\section{Sampling procedure}

Participants were sampled using a two-staged cluster sampling procedure in each settlement. The first stage involved selecting clusters of zones in the main settlement using systematic random sampling with probability proportional to zone size (PPS). The second stage constituted systematic sampling of households in selected zones. Random numbers procedures were used to choose one adult household member (i.e. 15 years and above) from among all adults in the household to constitute the final participant. This procedure resulted in 1014 refugees, with the following distribution among the settlements: Adjumani $n=342 ; K y a k a 354$; Kisenyi $n=318$.

\section{Ethical Considerations}

Thirty Research Assistants (RAs) were trained to collect data using mobile tablets, in a bid to reduce interindividual contact and the risk of COVID-19 spread during interviews. The training oriented RAs on the purpose of the study; ethical considerations; data collection methods and tools; COVID-19 prevention, symptoms, measures and precautions; and standard operating procedures (SOPs) in fieldwork in light of COVID-19. The training also involved testing of the data collection tool among a purposively selected refugee sample of $n=30$ in each of the 3 settlements, from zones neighboring but not included in the main study. Slight adjustments were made to data collection tools following this exercise.

Informed consent was received from all participants and confidentiality considered. The potential risk and benefits of the study were explained to all participants and in light of the heightened risk of COVID-19 transmission, we developed Standard Operational Procedures (SOPs) for protection of refugees as well as data collectors, guided by Safety and Security Strategy for COVID-19 of the World Health Organization (WHO) and Uganda Ministry of Health COVID-19 Guidelines.

The study was approved by the Makerere University School of Public Health Institutional Review Board (MakSPH IRB) and the Uganda National Council of Science and Technology (UNCST), the two bodies governing academic research in Uganda. Additionally, the Ministry of Health ( $\mathrm{MoH})$, Kampala Capital City Authority (KCCA) and the Office of the Prime Minister, which is in charge of refugee affairs, gave clearance for execution of the study.

Data collection tools and Study variables 
A comprehensive questionnaire covering several areas of relevance to public health and COVID-19 was developed. For the current study, the following variables were of interest:

\section{Dependent variables}

The dependent variable for the study was psychological distress, measured using Kessler's Psychological Distress Scale (K10)[48], a previously validated 10-item instrument measuring distress in terms of feelings of nervousness, hopelessness, tiredness, restlessness, fidgety, depressed mood, sadness, worthlessness, cheerlessness and loss of effort, during the past 14 days, with a 5 -level response ranging from none of the time (score 1 ) to all of the time (score 5). A composite score for depression is calculated for each participant as the sum of the 10 items. Thus, individual scores for depression scale ranged from 10-50, with higher scores indicative of higher depression risk. Cronbach's alpha testing for internal consistency/reliability of Kessler's Psychological Distress Scale for the current sample was 0.91 indicating very high reliability.

\section{Independent variables}

The main independent variable for this study was social support, with the aim to assess its direct impact on psychological distress, together with the assessment of its role in buffering the impact of living in various settlement categories (i.e. urban, rural, semi-rural settlement) on distress. Social support was measured using the Interview Schedule for Social Integration (ISSI) [49], which assesses social support in terms of the Availability and Adequacy of Social Interaction and Social Attachment.

Availability of Social Interaction was assessed using six items inquiring of participants to indicate the number of people: with whom they have common interest, meet and talk to regularly, can speak with openly, can borrow things from and can turn to when in trouble. This was thus a continuous scale ranging between 0 -infinity. The participants were in addition requested to rate the Adequacy of these numbers indicating whether they desire more (coded as 1), less (coded as 1) or no change (coded as zero) in the number indicated. Thus, Adequacy of Social Interaction was rated on a total scale ranging between $0-6$, with higher scores denoting higher inadequacy (i.e. poor adequacy). Cronbach's alpha testing for internal consistency/reliability of Availability and Adequacy of Social Interaction respectively for the current sample was 0.50 and 0.81 respectively, indicating moderate to high reliability respectively.

Availability of Social Attachment was assessed based on six items inquiring of participants to indicate using a "Yes" (coded as 1 ) or "No" (coded as 0 ) response regarding whether there is someone special: from whom they derive support, they feel close to, they share happy moments, they can embrace for comfort, appreciates what they do, and with whom they can share inner thoughts. For social attachment, composite individual scores are calculated as the sum of responses to each item. Thus, scores for social attachment range between $0-6$, with higher scores representing higher availability. Adequacy of Social Attachment was assessed by inquiries to participants on whether they desire more (coded 1), less (coded 1 ) or no change (coded 0 ) regarding the special persons mentioned above. Thus, scores for this scale ranged between $0-6$, with higher scores representing higher inadequacy (i.e. poor adequacy). Cronbach's 
alpha testing for internal consistency/reliability of Availability and Adequacy of social attachment respectively for the current sample was 0.55 and 0.87 respectively, indicating moderate to high reliability respectively.

Other independent variables included in the study were demographic, social and behavioral characteristics of participants, such as sex, age, marital status, religion, income, employment status, alcohol and substance use and physical activity. As these variables are from previous studies generally known to be associated both with social support and psychological distress, it is prudent to adjust for them in the main analyses in a bid to control for possible confounding.

\section{Statistical Analysis}

Cronbach's Alpha coefficients were calculated to assess for reliability of the instruments of interest (i.e. Kessler's Psychological Distress Scale and ISSI)in the current sample. In the assessment and contrasts of the burden of psychological distress in rural, semi-rural and urban refugee populations (research question 1), ANOVA was used. To compare the rates of availability and adequacy of social support among refugees in rural, semi-rural and urban settlements (research question 2), Analysis of Variance (ANOVA) were used. To assess for bivariate associations between Psychological distress and Social support indicators, demographic, social and behavioural independent variables, t-test, ANOVA and Pearsons Correlations tests were run.

In the assessment of the mechanism linking social support to distress (i.e. the direct effects and the stress buffering effects, research question 3), Multivariable Linear Regression (MLR) was used. In the assessment of the direct effect of Social Support on Psychological Distress, MLR including the entire study sample was run with psychological distress as the dependent variable and social support indicators as the main independent variables, but adjusting for independent effects of demographic (including urban/semi-rural/rural residency), social and behavioural factors on the dependent variable. The direct effect of social support would be confirmed if the social support indicators remained statistically significantly associated with distress despite adjustment for possible confounders.

The stress buffering effect was assessed using stratified MLR with settlement as the main independent variable, but controlling for demographic, social and behavioural factors. Stratification was by social support availability/adequacy levels categorized under "high" (defined as lacking in 1 or none of the 6 dimensions studied), "moderate"(i.e. lacking in 2 or 3 of the 6 dimensions studied), "low" (lacking in 4 of the 6 dimensions studied) and "very low" (lacking in 5 or 6 of the 6 dimensions studied). Social support would be considered as a stress buffer if it acted as an effect modifier in the association between psychological distress and urban/semi-rural/rural residency, i.e. if the association between refugee settlement (i.e. rural/urban residency) and psychological distress is stronger where support is weak and weaker where support is strong.

SPSS version 22 was used for all analyses and a statistical significance of $p<0.05$ was assumed for all tests. 


\section{Results}

\section{Demographic, social and behavioural characteristics of Participants}

Study participants were equally distributed across the rural, semi-rural and urban settlements of Adjumani, Kyaka IIand Kisenyi respectively (table 1). Majority of participants were of South-Sudanese, Congolese or Somali origin, with a specific nationality predominating in each settlement (i.e. the urban settlement of Kisenyi was dominated by Somalis (100\%), rural settlement of Adjumani dominated by South Sudanese (99\%), and semi rural settlement of Kyaka II dominated by Congolese (97\%).). Majority of the refugees were: aged under 45 years (over 80\%), of female sex (65\%), Protestants (36\%) and Moslems (30\%). Many refugees were unemployed (70\%), in the low-income bracket (i.e. 57\% earning less than 50,000 Uganda Shillings per week) and were uneducated (40\%). Concerning behavioral characteristics, few participants were smokers (4\%) or drank alcohol (7\%), but many (44\%) were physically inactive by way of exercise.

Participants ratings of Availability and Adequacy of Social Interaction by Settlement

On average, refugees rated their availability of social interaction rather high, ranging between 23-28 people across the settlements (table 2), with significantly higher availability ratings observed among refugees in urban followed by rural and lowest in semi-rural settlements respectively $[f(2,1011)=6.05 ; p<0.005]$. On the other hand, refugees rated adequacy of social interaction rather low (i.e. 3.9-4.2), on a scale of range 0-6. As higher scores denote higher grade of inadequacy, significantly higher adequacy of social interaction was observed for semi-rural residents followed by rural and lowest among urban residents respectively $[f(2,1011)=54.1 ; p<0.001]$. In summary, availability of social interaction was highest among refugees in urban settlements when contrasted with peers in rural and semi-rural settlements. On the other hand, adequacy of social interaction was higher among semi-rural and rural residents than urban peers. 
Refugees ratings of Availability and Adequacy of Social Attachment Overall and by Settlement

On average, refugees rated their availability of social attachment rather high (on average ranging between 5.2 - 5.4) on a scale of range 0 - 6) (table 2), with significantly higher ratings observed among urban followed by rural and lowest among semi-rural residents respectively $[f(2,1011)=47.9 ; p<0.001]$. On the other hand, refugees rated adequacy of social attachment rather low (i.e. 4.1-4.3). As higher scores denote higher grade of inadequacy, significantly higher adequacy of social attachment was observed for semi-rural residents followed by urban and lowest among rural residents respectively $[\mathrm{f}(2,1011)=$ 50.5; $\mathrm{p}<0.001]$. Overall, availability of social attachment was higher among refugees in urban settlements when contrasted with peers in rural and semi-rural settlements. On the other hand, adequacy of social interaction was higher among semi-rural and urban residents than rural peers.

Refugees ratings of Psychological Distress Overall and by Settlement

Levels of distress were on average moderate, ranging between 20.4-21.5 across settlements on a scale ranging from 10 - 50 (table 2). As higher scores denote higher distress, significantly higher psychological distress was observed among semi-rural followed by rural and lowest among urban residents respectively $[f(2,1011)=47.9 ; p<0.001]$.

Association between Psychological Distress and demographic, social and behavioural factors

Psychological distress levels varied significantly according to demographic, social and behavioural characteristics of refugees (table 3). Refugees of Congolese nationality, followed by Rwandese, Burundians and South Sudanese respectively exhibited significantly higher distress than refugees of Somali origin $[f(3,1010)=35.3 ; p<0.001]$ (table 3). These results mirror the previously presented findings (table 2) indicating that psychological distress varied between settlements, with higher distress traced to Semi-rural (where 
Congolese, Rwandese and Burundians are predominant) followed by rural (where SouthSudanese are predominant) and lowest in Urban (where Somalis are predominant) settlements respectively.

Female refugees reported, on average, higher distress levels than male peers [t $(1010)=$ 1.95; $\mathrm{p}=0.05$ ]while Protestants, Catholics and other religions exhibited on average higher distress levels than Moslems $[f(3,1010)=28.3 ; p<0.001]$. Unemployed refugees exhibited significantly higher psychological distress levels than peers in employment activity or studying $[f(4,1009)=7.0 ; p<0.001]$. Pearsons Correlation Coefficients $(r)$ showed that psychological distress increased with increasing age $[\mathrm{r}=0.18 ; \mathrm{p}<0.01]$, reduced with increasing level of education $[r=-0.20 ; p<0.001]$, and reduced with increasing level of physical activity $[\mathrm{r}=-0.25 ; \mathrm{p}<0.001]$ among the refugees.

Bivariate association between Social Interaction, Social Attachment and Psychological Distress

There was significant correlation between Psychological distress levels and social support indicators (table 3). Adequacy of social interaction exhibited a negative correlation with psychological distress (i.e. distress levels reduced as adequacy of social interaction increased) $[\mathrm{r}=-0.18 ; \mathrm{p}<0.01]$. Availability of social attachment exhibited a negative correlation with distress (i.e. psychological distress levels reduced as availability of social attachment increased $)[r=-0.18 ; \mathrm{p}<0.01]$. Similarly, as adequacy of social attachment increased, distress levels reduced $[\mathrm{r}=-0.16 ; \mathrm{p}<0.01]$.

Multiple Linear Regressions Analysis assessing the direct effect of Social Support on Psychological Distress

As indicated in Table 4, Adequacy of Social Interaction and Adequacy of Social Attachment were associated with Psychological Distress after controlling for plausible demographic, social and behavioural confounders. With increasing inadequacy in both respects, Psychological Distress increased. Availability of Social Interaction and Availability of Social 
attachment on the other hand were not significantly associated with Psychological Distress after controlling for plausible demographic, social and behavioural confounders. Thus, the direct effect of Social Support on Psychological Distress hypothesis was confirmed for Adequacy but not for Availability of support networks.

Stratified Multiple Linear Regressions Analysis assessing the buffering effect of Social Support in the association between Settlement and Psychological Distress

Since Availability of Social Interaction and Availability of Social Attachment were not independently associated with Psychological Distress in the previous regressions analyses, they are not included in the stratified analyses. In the following analyses therefore, stratified analyses are run for Adequacy of Social Interaction and Adequacy of Social Attachment respectively. As indicated in Table 5, the association between settlement and psychological distress remained statistically significant in the overall and in stratified analyses according to levels of Adequacy of Social Interaction. However, the strength of association particularly for the rural/urban contrasts increased progressively between the stratified analyses for high (i.e. $\mathrm{B}=0.21$ ), moderate (i.e. $\mathrm{B}=0.30$ ), and low (i.e. $\mathrm{B}=0.32$ ) levels of Adequacy of Social Interaction (expressed by the size of the standardized regression coefficients B). A similar trend was observed with regard to the analyses stratified by levels of Adequacy of Social Attachment, i.e. the strength of association particularly for the rural/urban contrasts increased progressively between the stratified analyses for high (i.e. $B=0.09$ ), moderate (i.e. $B=0.25$ ), and low (i.e. $B=0.29$ ) levels of Adequacy of Social Attachment. These findings are congruent with the stress buffering hypothesis i.e. the association between settlement (i.e. rural/urban residency) is stronger where adequacy of social interaction and adequacy of social attachment respectively is low and weaker where adequacy of such support is high. 


\section{Discussion}

Few studies in refugee settings have scrutinised the individual level social resources available to refugees and how these may manifest on their psychological wellbeing. Accordingly, we assessed the burden of psychological distress and scrutinized the mechanisms linking social support to distress among refugees resident in urban, semi-rural and rural settlements in Uganda.

\section{Burden of Psychological Distress in Urban, Semi-rural and Rural Refugee Settlements}

Levels of psychological distress were on average moderate among refugees, but with notable variations across settlements, i.e. significantly higher distress levels were observed among refugees resident in semi-rural and rural settings when contrasted with peers resident in urban settlements. While such data, to the best of our knowledge is previously lacking in refugee cohorts, population studies have generated contradictory results in this respect. Some scholars have supported the notion of heightened psychological distress in urban areas due to stressors related with urbanization such as unemployment, violence, marginalization, discrimination and increased exposure to health-risk behaviours, while other researchers have envisioned residents in urban settings to have an upper edge in health as a result of better access to health and social services in urban than in rural settings [30-32]. Our findings could be a reflection of the latter circumstances.

\section{Availability and Adequacy of Social Interaction and Social Attachment in Urban, Semi-rural and Rural Refugee Settlements}

Refugees rated their availability of social interaction (which encompassed access to resources required for regular social activities such as conversation and meeting people) and availability of social attachment (which covered access to social relations of emotional relevance such as embracing for comfort and sharing inner thoughts) as high, but rated adequacy of such resources (i.e. whether such resources were perceived sufficient) as low. Moreover, the results from the regressions analyses found adequacy of social interaction/attachment rather than availability of social interaction/attachment to correlate positively with psychological distress (i.e. with increasing adequacy, levels of distress reduced). Corroborating previous research in general population studies [50-51], these findings contribute new data to the refugee literature demonstrating that the effectiveness of social support in moderation of psychological distress among refugees is anchored on the perceived meaning and value of the support network (here measured by adequacy of social interaction and attachment), rather than the support network's morphological aspects (e.g. density and size of the network).

Availability of social interaction and attachment was highest among refugees residing in urban settlements when contrasted with peers residing in rural and semi-rural settlements. A plausible explanation for this result could stem from the fact that urban refugees lived in integrated rather than separate settlements with the host communities, and this may have provided opportunities for social networking with host community members, to a higher extent than in rural settlements where the residential areas are distinctively for refugees. On the other hand, adequacy of social interaction and 
attachment was highest among refugees resident in semi-rural and rural settlements when contrasted with peers resident in urban settlements. These results are more difficult to reconcile. While the findings linking availability of support networks to urban settlement are largely congruent with previous works in general populations [30-32], the findings linking adequacy of support to rural settings appear to contradict those works. Social support is a multi-dimensional concept and discrepancies in results across studies could stem from variations in its conceptualization between the studies. For instance, some studies have measured social support in terms of the form of support received (e.g. emotional support, instrumental support, cognitive guidance, informative and appraisal support) [52-53], while others have focussed on the morphology of the network (e.g. size) [50-51], or value of relationships within the network (e.g. relationship reciprocity) [54]. Thus, cross-study comparisons should be done with caution.

\section{Mechanisms Linking Social Support to Psychological Distress in Urban, Semi-rural and Rural Refugee Settlements}

The regressions analyses ruled out availability of social interaction and availability of social attachment respectively as independent predictors of Psychological Distress, but confirmed adequacy of social interactions and adequacy of social attachment respectively as predictors of such distress, i.e. Psychological Distress levels reduced as adequacy of social interaction and adequacy of social attachment respectively increased. Furthermore, our study generated evidence in support of the stress buffering function of social support [22-23], which postulates that the deleterious effects of psychosocial stressors on health can be reduced or eliminated with the existence of a strong support network. Specifically, we hypothesized and demonstrated that social support can moderate the impact of stressors due to rural/urban settlement on psychological distress in refugee populations.

\section{Implications and Recommendations}

The burden of psychological distress and social support in refugee settings drum for the need of surveillance of these phenomena as a basis for informed action. The need to revitalize, strengthen or restructure existing social networks cannot be overemphasised, with observance of COVID-19 prevention measures notwithstanding. Humanitarian actors will need to invest more in mental health and psychosocial support services (MHPSS), tailoring these interventions to the unique needs of different refugee categories. The leveraging of professionals across disciplines (e.g. social workers, psychologists, community health-workers) to be more actively involved in the MHPSS response to distress is apparent, particularly in rural/semi-rural refugee settings, during this COVID-19 era where refugees' access to the natural individual support networks (e.g. relatives and friends) have been temporarily constrained by government directives. A multi-sectoral team including main actors in humanitarian settings, should be set up to address how such measures can be implemented without necessarily exposing refugees to increased risk of COVID-19 alongside other challenges to implementation.

Moreover, the findings confirming the direct and buffering hypotheses of social support have important implications for interventions to manage distress in refugee settings. Firstly, the direct pathway linking specific aspects of social support (i.e. inadequacy) to psychological distress provides new evidence to 
support the design of focused (as opposed to generic) interventions, aimed at strengthening social support among refugees. In addition, the study has demonstrated the potential utility of the stress buffer framework of social support in the identification of irreversible stressor in refugees' lives (e.g. settlement in urban/rural settings) that could lead to psychological distress. Moreover, social support could, within such frameworks, be applied to predict the thresholds at which such stressors may lead to severe psychological distress, information of importance in early detection and prevention strategies.

\section{Study Limitations}

While the study carried the strength of a large representative sample of refugees in Uganda, utilized validated instrumentation and applied conventional statistical methodology to respond to the research questions, some of its weaknesses deserve acknowledgement. First, the cross-sectional design does not permit inference of causality, which is implied in some of the hypotheses tested. For instances, we can only firmly ascertain associations between social support and distress. Secondly, the homogenous cultural composition of refugees in each of the studied settlements (i.e. predominance of Somalis in the urban settlement vs. South Sudanese and Congolese in the rural and semi-rural settlements respectively) makes it difficult to disentangle associations between distress and urban/rural settlement on the one hand from associations between distress and country of origin on the other hand. Thus, the observed differences in distress between settlements could be masking differences in distress due to nationality. Due to the presence of collinearity in our data with regard to these two variables (i.e. settlement and nationality), we could not address this question by way of analysis. Future research focussing on the separation of these two effects is warranted using the appropriate study design.

\section{Conclusion}

There is a settlement inequality (i.e. rural vs. urban) in psychological distress and social support among conflict refugees in Uganda. Both the direct and the buffering effects of adequacy of social interaction and attachment can be forwarded to explain the rural/urban discrepancy in psychological distress, with important implications for Mental Health and Psychosocial Support (MHPSS) interventions.

\section{Declarations}

\section{Ethics approval and consent to participate}

The study was approved by the Makerere University School of Public Health Institutional Review Board (MakSPH IRB) and the Uganda National Council of Science and Technology (UNCST), the two bodies governing academic research in Uganda. Informed consent was obtained from each participant.

\section{Consent for publication}

Not Applicable 
The datasets used and/or analysed during the current study are available from the corresponding author on reasonable request.

\section{Competing interests}

None to declare

\section{Funding}

The study was funded through a research grant received by the authors from Research for Health in Humanitarian Crises (R2HC)/Elrha, supported bythe UK Foreign, Commonwealth and Development Office (FCDO),Wellcome, and the National Institutefor Health Research (NIHR).

\section{Authors' contributions}

SL and GS conceptualized this study. EL, MS, DD, AM, BL, EO, BO and DM were responsible for data collection, cleaning and management at respective refugee settlements. SL and CL performed the literature review. SL and EL performed the statistical analyses. SL, CL and GS wrote the first draft of the paper. All authors contributed to the consequent drafts draft of the paper.

\section{Acknowledgements}

The authors are grateful to R2HC/Elrha and funding partners for financial support tothe project "REFugee Lived Experiences, Compliance and Thinking (REFLECT) in COVID-19", of which the current study is part.

\section{References}

1. Dubey S, Biswas P, Ghosh R, Chatterjee S, Dubey MJ, Chatterjee S, Lahiri D, Lavie CJ. Psychosocial impact of COVID-19. Diabetes metabolic syndrome. 2020;14(5):779-88. https://doi.org/10.1016/j.dsx.2020.05.035.

2. Hamza Shuja K, Aqeel M, Jaffar A, Ahmed A. COVID-19 pandemic and impending global mental health implications. PsychiatriaDanubina. 2020;32(1):32-5.

3. Josephson A, Kilic T, Michler JD. (2021). Socioeconomic impacts of COVID-19 in low-income countries. Nature Human Behaviour, 1-9.

4. Kansiime MK, Tambo JA, Mugambi I, Bundi M, Kara A, Owuor C. COVID-19 implications on household income and food security in Kenya and Uganda: Findings from a rapid assessment. World development. 2021;137:105199.

5. Kola L. Global mental health and COVID-19. The Lancet Psychiatry. 2020;7(8):655-7.

6. Torales J, O'Higgins M, Castaldelli-Maia JM, Ventriglio A. The outbreak of COVID-19 coronavirus and its impact on global mental health. Int J Soc Psychiatry. 2020;66(4):317-20. 
https://doi.org/10.1177/0020764020915212.

7. UNDP. (2020). The socio-economic impact of COVID-19 in Uganda: short-term and long-term impact on poverty dynamics and SDGs using scenario analysis and system dynamics modelling. Available at: file:///C:/Users/katel/AppData/Local/Temp/Socio-Economic-Impact-COVID-19-Uganda-Brief-1UNDP-Uganda-April-2020.pdf.

8. Kumar D, Tahir Saghir GA, Yasin U, Furnaz S, Karim M, Hussain M, ... Kumar H. Psychosocial Impact of COVID-19 on Healthcare Workers at a Tertiary Care Cardiac Center of Karachi Pakistan. J Occup Environ Med. 2021;63(2):e59.

9. Marazziti D, Pozza A, Di Giuseppe M, Conversano C. The psychosocial impact of COVID-19 pandemic in Italy: A lesson for mental health prevention in the first severely hit European country. Psychological Trauma: Theory Research Practice Policy. 2020;12(5):531.

10. Ogrodniczuk JS, Rice SM, Kealy D, Seidler ZE, Delara M, Oliffe JL. (2021). Psychosocial impact of the COVID-19 pandemic: A cross-sectional study of online help-seeking Canadian men. Postgraduate Medicine.

11. Saha K, Torous J, Caine ED, De Choudhury M. Psychosocial Effects of the COVID-19 Pandemic: Large-scale Quasi-Experimental Study on Social Media. J Med Internet Res. 2020;22(11):e22600.

12. Saladino V, Algeri D, Auriemma V. The psychological and social impact of Covid-19: new perspectives of well-being. Frontiers in psychology. 2020;11:2550.

13. Tol WA, Patel V, Tomlinson M, Baingana F, Galappatti A, Panter-Brick C, Silove D, Sondorp E, Wessells $\mathrm{M}$, Van Ommeren $\mathrm{M}$. Research priorities for mental health and psychosocial support in humanitarian settings. PLoS Med. 2011 Sep;20(9):e1001096. 8(.

14. Tol WA, Barbui C, Galappatti A, Silove D, Betancourt TS, Souza R, Golaz A, Van Ommeren M. Mental health and psychosocial support in humanitarian settings: linking practice and research. The Lancet. 2011 Oct;29(9802):1581-91. 378(.

15. San Lau L, Samari G, Moresky RT, Casey SE, Kachur SP, Roberts LF, Zard M. COVID-19 in humanitarian settings and lessons learned from past epidemics. Nat Med. 2020 May;26(5):647-8.

16. Blanchet K, Sistenich V, Ramesh A, Frison S, Warren E, Hossain M, Knight A, Lewis C, Smith J, Woodward A, Dahab M. An evidence review of research on health interventions in humanitarian crises. 22. London: London School of Hygiene \& Tropical Medicine; 2013 Nov.

17. Williams RE, Black CL, Kim HY, Andrews EB, Mangel AW, Buda JJ, Cook SF. Determinants of healthcare-seeking behaviour among subjects with irritable bowel syndrome. Alimentary pharmacology \& therapeutics. 2006 Jun;23(11):1667-75.

18. Barnes DM, Almasy N. Refugees' perceptions of healthy behaviors. Journal of Immigrant Health. 2005 Jul 1;7(3):185-93.

19. Turrini G, Purgato M, Acarturk C, Anttila M, Au T, Ballette F, Bird M, Carswell K, Churchill R, Cuijpers P, Hall J. Efficacy and acceptability of psychosocial interventions in asylum seekers and refugees: systematic review and meta-analysis. Epidemiology psychiatric sciences. 2019 Aug;28(4):376-88. 
20. Tribe RH, Sendt KV, Tracy DK. A systematic review of psychosocial interventions for adult refugees and asylum seekers. Journal of Mental Health. 2019 Nov 2;28(6):662-76.

21. Nwadiora E, McAdoo H. Acculturative stress among Amerasian refugees: Gender and racial differences. Adolescence. 1996 Jul 1;31(122):477.

22. Cohen S, Wills TA. Stress, social support, and the buffering hypothesis. Psychological bulletin. 1985 Sep;98(2):310.

23. Hobfoll SE. Limitations of social support in the stress process. InSocial support: Theory, research and applications 1985 (pp. 391-414). Springer, Dordrecht.

24. Hirsch BJ. Natural support systems and coping with major life changes. Am J Community Psychol. 1980 Apr;8(2):159-72.

25. Roskies E, Lazarus RS. Coping theory and the teaching of coping skills. Behavioral medicine: Changing health lifestyles. 1980:38-69.

26. Rabin BS, Rabin BC. Stress, immune function, and health: The connection. 5: Wiley-Liss; 1999 Mar.

27. Rankin SH, Monahan P. Great expectations: perceived social support in couples experiencing cardiac surgery. Fam Relat. 1991 Jul;1:297-302.

28. Wortman CB, Lehman DR. Reactions to victims of life crisis: support attempts that fail. In Sarason, editor IG, Sarason.

29. BR, eds. Social support: theory, research and applications. The Hague: MartinusNijhoff, 1985: 463_/89.

30. Hobfoll SE, Leiberman Y. Personality and social resources in immediate and continued stress resistance.

31. among women. J Pers Soc Psychol. 1987;52:18_/26.

32. Leviton LC, Snell E, McGinnis M. Urban issues in health promotion strategies. AmJPublic Health. 2000;90:863-6.

33. Geronimus AT. To mitigate, resist, or undo: addressing structural influences on thehealth of urban populations.Am. J Public Health. 2000;90:867-72.

34. Vlahov D, Galea S. Urbanization, urbanicity, and health. Journal of Urban Health. 2002 Mar;79(1):12.

35. Taylor SE, Sherman DK, Kim HS, Jarcho J, Takagi K, Dunagan MS. Culture and social support: Who seeks it and why? J Personal Soc Psychol. 2004 Sep;87(3):354.

36. Godfrey R, Julien M. Urbanisation and health. Clinical Medicine. 2005 Mar 1;5(2):137.

37. UNHCR. Figures. at a glance https://www.unhcr.org/figures-at-a-glance.html (accessed May 2021).

38. Ahimbisibwe F. Uganda and the refugee problem: Challenges and opportunities. Institute of Development Policy and Management (IOB), University of Antwerp, Working Paper No. 2018 May.

39. Monteith W, Lwasa S. The participation of urban displaced populations in (in) formal markets: contrasting experiences in Kampala, Uganda. Environment Urbanization. 2017;29(2):383-402. 
40. Peltzer K. Trauma and mental health problems of Sudanese refugees in Uganda. The Central African journal of medicine. 1999 May 1;45(5):110-4.

41. Hovil L. Self-settled refugees in Uganda: An alternative approach to displacement? Journal of Refugee Studies. 2007 Dec;20(4)(1):599-620.

42. Kaiser T. Between a camp and a hard place: rights, livelihood and experiences of the local settlement system for long-term refugees in Uganda. Journal of Modern African Studies. 2006 Dec 1:597-621.

43. Ministry of Health. (2020). COVID-19 response info hub. Available from: https://covid19.gou.go.ug/timeline.html.

44. Nakalembe JS. (2020). Covid 19 interventions verses a woman in Uganda [Internet]. Stop Gender Based Violence [cited 2021 Apr 20]. Available at:https://www.cehurd.org/covid-19-interventionsverses-a-woman-in-uganda/.

45. Gato J. (2020). The Effects of COVID-19 Lockdown on Urban Refugees in Kampala. [Internet]. Available at: https://blog.fluchtforschung.net/covid-19-lockdown-on-urban-refugees-in-kampala/ .

46. Bukuluki P, Mwenyango H, Katongole SP, Sidhva D, Palattiyil G. The socio-economic and psychosocial impact of Covid-19 pandemic on urban refugees in Uganda. Social Sciences Humanities Open. 2020;2(1):100045.

47. Guadagno L. Migrants and the COVID-19 pandemic: An initial analysis. Geneva: International Organization for Migration; 2020. p. 60.

48. Truelove S, Abrahim O, Altare C, Lauer SA, Grantz KH, Azman AS, Spiegel P. The potential impact of COVID-19 in refugee camps in Bangladesh and beyond: a modeling study. PLoS Med. 2020;17(6):e1003144.

49. Tsamakis, K., Tsiptsios, D., Ouranidis, A., Mueller, C., Schizas, D., Terniotis, C.,... Rizos, E. (2021). COVID19 and its consequences on mental health. Experimental and therapeutic medicine, 21(3), 11.

50. Kessler RC, Andrews G, Colpe LJ, Hiripi E, D K MR, T NORMAND SL, WALTERS EE, Zaslavsky AM. Short screening scales to monitor population prevalences and trends in non-specific psychological distress. Psychological medicine. 2002 Aug 1;32(6):959.

51. Henderson S, Duncan-Jones P, Byrne DG, Scott R. Measuring social relationships the interview schedule for social interaction. Psychological medicine. 1980 Nov;10(4):723-34.

52. Kaplan BH, Cassel JC, Gore S. Social support and health. Medical care. 1977 May 1;15(5):47-58.

53. Berkman LF, Syme SL. Social networks, host resistance, and mortality: a nine-year follow-up study of Alameda County residents. American journal of Epidemiology. 1979 Feb;109(2)(1):186-204.

54. Hirsch BJ. Natural support systems and coping with major life changes. Am J Community Psychol. 1980 Apr;8(2):159-72.

55. Norbeck JS, Lindsey AM, Carrieri VL. The development of an instrument to measure social support. Nursing research. 1981 Sep. 
56. Cohen S, Wills TA. Stress, social support, and the buffering hypothesis. Psychological bulletin. 1985 Sep;98(2):310.

\section{Tables}

Table 1: Demographic, Social and Behavioural Characteristics of Participants 


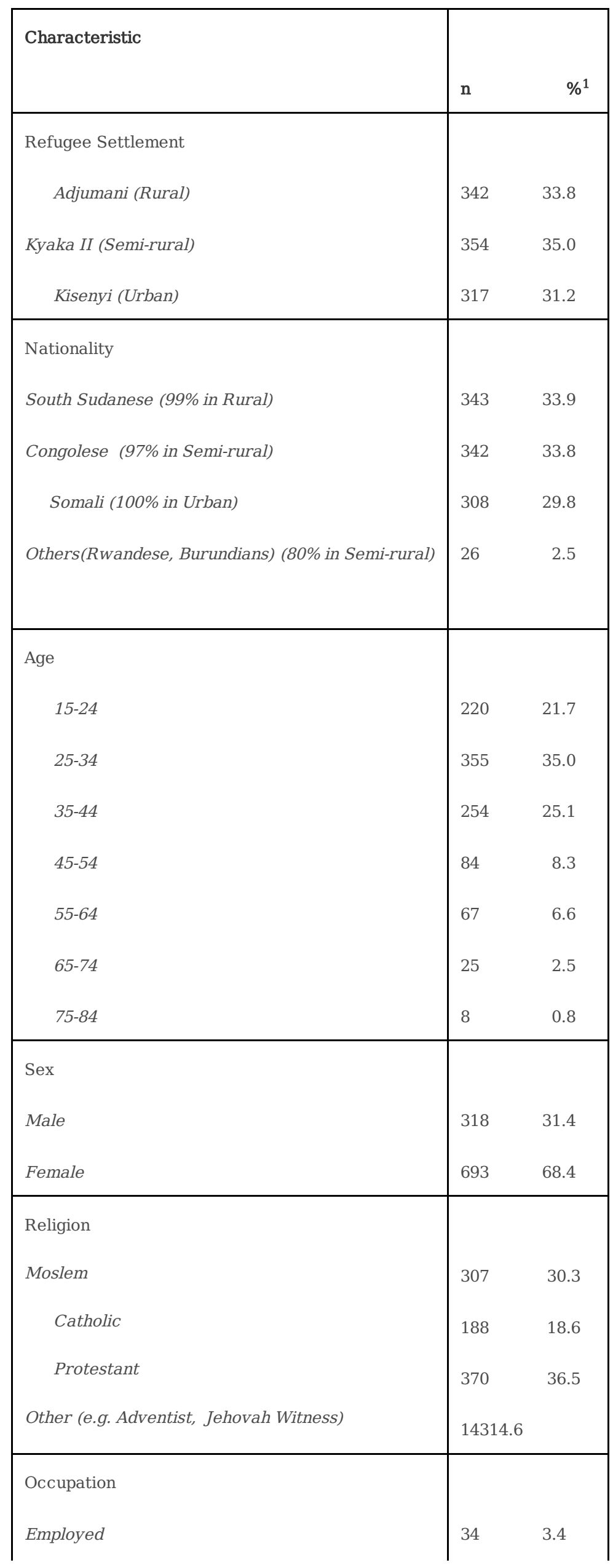

Page 21/26 


\begin{tabular}{|c|c|c|}
\hline Self-employed & 120 & 11.9 \\
\hline Unemployed & 712 & 70.3 \\
\hline Student & 113 & 11.2 \\
\hline Other (shifting e.g. vendor, retailer etc) & 32 & 3.1 \\
\hline \multicolumn{3}{|l|}{ Earnings per week } \\
\hline Less than 50,000 & 577 & 57.1 \\
\hline $50,000-100,000$ & 87 & 8.7 \\
\hline $100,000-200,000$ & 35 & 3.5 \\
\hline Over 200,000 & 33 & 3.3 \\
\hline \multicolumn{3}{|l|}{ Highest Education Level } \\
\hline No Education & 407 & 40.2 \\
\hline Primary level & 303 & 29.9 \\
\hline Secondary level & 230 & 22.7 \\
\hline Tertiary or vocational & 24 & 2.4 \\
\hline University & 46 & 4.5 \\
\hline \multicolumn{3}{|l|}{ Smoker } \\
\hline Yes & 38 & 3.8 \\
\hline No & 970 & 95.8 \\
\hline \multicolumn{3}{|l|}{ Drink Alcohol } \\
\hline Yes & 72 & 7.2 \\
\hline No & 931 & 91.9 \\
\hline \multicolumn{3}{|l|}{ Exercise } \\
\hline Never & 450 & 44.4 \\
\hline Once & 175 & 17.3 \\
\hline 2-3 times & 258 & 24.5 \\
\hline 4 times or more & 127 & 12.5 \\
\hline
\end{tabular}

${ }^{1}$ Percentages may not add up to $100 \%$ due to missing values

Table 2: Refugees ratings of levels of Social Support and Psychological Distress: Overall and by settlement 


\begin{tabular}{|l|l|l|l|l|}
\hline Variable & \multicolumn{1}{|c|}{ Rural } & Semi-rural & Urban & Total \\
(Range) & Mean (CI) & Mean (CI) & Mean (CI) & Mean (CI) \\
\hline Availability of Social Interaction** & $25.6(21.7-29.5)$ & $20.8(17.2-24.4)$ & $30.9(26.5-35.5)$ & $25.9(23.6-28.3)$ \\
\hline (0 - infinity) & $4.3(4.1-4.5)$ & $3.1(2.9-3.4)$ & $4.6(4.4-4.8)$ & $4.0(3.9-4.2)$ \\
\hline $\begin{array}{l}\text { Adequacy of Social Interaction*** } \\
\text { (0 - 6) }\end{array}$ & $5.3(5.0-5.5)$ & $4.9(4.8-5.1)$ & $5.7(5.5-5.9)$ & $5.3(5.2-5.4)$ \\
\hline Availability of Social Attachment*** \\
$(0-6)$
\end{tabular}

**ANOVA f-test statistically significant at $\mathrm{p}<0.01$; *** ANOVA f-test statistically significant at $\mathrm{p}<0.001$

Table 3: Bivariate association between demographic, socio-behavioural and social support indicators and Psychological Distress 


\begin{tabular}{|c|c|}
\hline Characteristic & Mean (SE) \\
\hline \multicolumn{2}{|l|}{ Nationality*** } \\
\hline South Sudanese & $21.4(0.5)$ \\
\hline Congolese & $23.7(0.5)$ \\
\hline Somali & $16.9(0.3)$ \\
\hline Other (i.e. Rwandese, Burundians) & $23.6(1.8)$ \\
\hline \multicolumn{2}{|l|}{ Sex* } \\
\hline Female & $21.3(0.3)$ \\
\hline Male & $20.1(0.5)$ \\
\hline \multicolumn{2}{|l|}{ Religion*** } \\
\hline Moslem & $16.9(0.4)$ \\
\hline Catholic & $22.4(0.7)$ \\
\hline Protestant & $23.3(0.5)$ \\
\hline Other (e.g. Adventist, Jehovah Witness) & $21.1(0.7)$ \\
\hline \multicolumn{2}{|l|}{ Occupation*** } \\
\hline FormalEmployed & $17.5(1.3)$ \\
\hline Self-employed & $18.7(0.6)$ \\
\hline Unemployed & $21.9(0.3)$ \\
\hline Student & $18.7(0.8)$ \\
\hline \multirow[t]{2}{*}{ Other (shifting e.g. vendor, retailer etc) } & $19.8(1.3)$ \\
\hline & Pearsons Correlation Coefficient ( $r$ ) \\
\hline Age (Years) $* *$ & 0.18 \\
\hline Earnings per week (Shillings) & -0.02 \\
\hline Highest Education Level** & -0.20 \\
\hline Smoking (Yes/No) & -0.04 \\
\hline
\end{tabular}

Page 24/26 


\begin{tabular}{|l|l|} 
& -0.02 \\
\hline Drink Alcohol (Yes/No) & \\
\hline Availability of Social Interaction & -0.25 \\
\hline Adequacy of Social Interaction** & \\
\hline Availability of Social Attachment** & -0.04 \\
\hline Adequacy of Social Attachment* & -0.18 \\
\hline
\end{tabular}

*T-test for difference in means or Correlation Coefficient ( $r$ ) statistically significant at $\mathrm{p}<0.05$; ** ANOVA f-test or Correlation Coefficient ( $\mathrm{r}$ ) statistically significant at $\mathrm{p}<0.01$

Table 4: Adjusted Standardized Regression Coefficients (Standardized Beta) assessing independent associations between Social Support indicators and Psychological Distress

\begin{tabular}{|l|l|}
\hline Characteristic & Standardized Beta ${ }^{1}$ \\
\hline Availability of Social Interaction & -0.02 \\
\hline Adequacy of Social Interaction** & 0.11 \\
\hline Availability of Social Attachment & -0.02 \\
\hline Adequacy of Social Attachment** & 0.10 \\
\hline
\end{tabular}

${ }^{1}$ The analysis was adjusted for settlement, sex, religion, occupation, age, education level and physical activity. Due to high collinearity between nationality and settlement, nationality was excluded from the analysis

Table 5: Adjusted Standardized Regression Coefficients (B) assessing buffering effect of Social Support indicators in the association between Settlement and Psychological Distress 


\begin{tabular}{|c|c|c|c|c|c|}
\hline & \multirow{2}{*}{$\begin{array}{l}\text { Un-stratified Analysis } \\
\\
\mathrm{B}^{1}\end{array}$} & \multicolumn{4}{|c|}{$\begin{array}{l}\text { Analysis Stratified by Levels of Adequacy of Social Interaction } \\
\text { (High, Moderate, Low, Very Low) }\end{array}$} \\
\hline & & $\begin{array}{l}\text { High } \\
\mathrm{B}^{1}\end{array}$ & $\begin{array}{l}\text { Moderate } \\
\mathrm{B}^{1}\end{array}$ & $\begin{array}{l}\text { Low } \\
\mathrm{B}^{1}\end{array}$ & $\begin{array}{l}\text { Very Low } \\
\mathrm{B}^{1}\end{array}$ \\
\hline \multicolumn{6}{|l|}{ Settlement } \\
\hline Rural & $0.22^{* *}$ & $0.21 * *$ & $0.30 * *$ & $0.32 * *$ & 0.01 \\
\hline Semi-rural & $0.40^{* * *}$ & $0.34^{* * *}$ & 0.12 & 0.05 & $0.28^{* * *}$ \\
\hline \multirow[t]{3}{*}{ Urban (ref) } & ref & ref & ref & ref & ref \\
\hline & Un-stratified Analysis & \multicolumn{4}{|c|}{$\begin{array}{c}\text { Analysis Stratified by Levels of Adequacy of Social Attachment } \\
\text { (High, Moderate, Low, Very Low) }\end{array}$} \\
\hline & $\mathrm{B}^{1}$ & $\begin{array}{l}\text { High } \\
\mathrm{B}^{1}\end{array}$ & $\begin{array}{l}\text { Moderate } \\
\mathrm{B}^{1}\end{array}$ & $\begin{array}{l}\text { Low } \\
\mathrm{B}^{1}\end{array}$ & $\begin{array}{l}\text { Very Low } \\
\mathrm{B}^{1}\end{array}$ \\
\hline \multicolumn{6}{|l|}{ Settlement } \\
\hline Rural & $0.22^{* *}$ & 0.09 & $0.25^{* *}$ & $0.39 * * *$ & $0.18^{*}$ \\
\hline Semi-rural & $0.40^{* * *}$ & $0.29^{* *}$ & $0.29 * *$ & $0.17 *$ & $0.22 * * *$ \\
\hline Urban (ref) & ref & ref & ref & ref & Ref \\
\hline
\end{tabular}

${ }^{1}$ Standardized and adjusted for sex, religion, occupation, age, education level and physical activity 